\title{
Fusarium species associated with cob rot of sweet corn and maize in New South Wales
}

\author{
A. Watson • L. W. Burgess • B. A. Summerell • \\ K. O'Keeffe
}

Received: 5 June 2014 / Accepted: 17 July 2014 /Published online: 27 July 2014

(C) Australasian Plant Pathology Society Inc. 2014

\begin{abstract}
Cob rot epidemics occurred in NSW in sweet corn in 2002 and maize in 2003. Investigations were undertaken to establish the species of Fusarium associated with both instances. Dependent on region, $F$. verticillioides, $F$. proliferatum, and $F$. subglutinans were isolated more frequently. The epidemics were unique in their occurrence being in two corn types, in consecutive years, and in two regions.
\end{abstract}

Keywords Fusarium · Maize · Corn · Sweet corn · Fumonisin

The main maize (Zea mays) production areas in New South Wales (NSW), Australia are located in the Liverpool Plains and Moree areas of the northern grain belt, and around Griffith in the Murrumbidgee Irrigation Area (MIA) of southern NSW (O'Keeffe 2011). A large proportion of maize in the MIA is grown utilising furrow irrigation, whereas overhead irrigation, such as linear systems or centre pivots, are utilised in other areas of the state.

Sweet corn (Zea mays var. rugosa) for processing is grown in localised areas in NSW, around Dubbo, Bathurst, Cowra, and in the MIA. Maize hybrids are grown for various end uses such as grain or silage for stockfeed, breakfast cereals, corn

A. Watson $(\bowtie)$

NSW Department of Primary Industries, Yanco Agricultural

Institute, Yanco 2703, NSW, Australia

e-mail: andrew.watson@dpi.nsw.gov.au

\section{W. Burgess}

Faculty of Agriculture, Food and Natural Resources, University of Sydney, Sydney 2006, NSW, Australia

B. A. Summerell

Royal Botanic Gardens and Domain Trust, Mrs Macquaries Road,

Sydney 2000, NSW, Australia

K. O'Keeffe

CottonInfo, Griffith 2680, NSW, Australia chips, starch and flour. Sweet corn is grown for fresh consumption or for processing. In NSW, maize and sweet corn are grown over the summer months. They are planted in OctoberDecember and harvested February-April, therefore a season commences in one calendar year and finishes in the next.

Root, stalk and cob rot of corn is most commonly caused by Fusarium graminearum, F. verticillioides, F. proliferatum and F. subglutinans (Leslie and Summerell 2006). Fusarium species can infect corn plants through the seed, silks, stalks and roots and endophytic colonization is common, that is, the fungus is able to grow within the plant without producing symptoms until plant stress induces disease development (Bacon et al. 1996; White 1999).

Fusarium species produce a range of mycotoxins. For example, $F$. verticillioides and $F$. proliferatum produce fumonisins which can affect horses and pigs, and have been associated with oesophageal cancer in humans (Desjardins 2006). Mouldy grain infected with $F$. verticillioides has produced equine leukoencephalomalacia (blind staggers) in horses from Australia (NSW) that subsequently died (Shanks et al. 1995). In 2002, processing sweet corn crops in the Dubbo area of NSW were severely affected by cob rot and some crops were rejected by the processors. White-to-salmon pigmented fungal growth had developed over the kernels of some diseased cobs. The incidence of cob rot appeared to be much higher in the cultivar Golden Millennium than in the cultivar Jubilee. Field observations indicated that the cob rot was caused by one or more Fusarium species and preliminary diagnostic studies indicated that $F$. verticillioides was associated with the cob rot, however many other fungal and bacterial contaminants were isolated, some presumably as saprophytic colonisers. Nguyen (2005) found that $F$. verticillioides was commonly associated endophytically with sweet corn stalks and peduncles.

In February 2003, a number of maize crops were reportedly affected by Fusarium cob rot in the MIA, the first incidence of 
this type in the region. Stockfeed companies that were buying the grain rejected many loads based on the National Agricultural Commodity Marketing Association (NACMAR) industry standard that states that there is "nil tolerance to mouldy grain". The infected grain was brown-coloured compared to the bright yellow healthy maize kernels (Fig. 1).

Little is known of the extent of cob rot of maize or sweet corn or the species of Fusarium associated with these diseases in NSW. Consequently a survey was undertaken in the $2002 / 2003$ growing season to isolate and identify the Fusarium species associated with corn plants (stalks) as endophytes and also the species associated with kernel infection on cobs. The survey of sweet corn was to be conducted due to the issues experienced in 2001/2002, but as the maize epidemic appeared, investigations into this outbreak were also conducted.

Sweet corn plant material was collected from the field, taken to the laboratory and processed for isolation of Fusarium species. A $10 \mathrm{~cm}$ section of each stalk, including the first node, was removed and surface sterilised by swabbing with $100 \%$ ethanol. The stalk was cut transversely at the node to give a $5 \mathrm{~mm}$-thick cross-section (disc). A wedge-shaped segment was then removed aseptically from the cross-section and plated onto Peptone-Pentachloronitrobenzene Agar (PPA) (Burgess et al. 1994), a selective agar medium for Fusarium species. Fifty cobs with peduncles (also called shanks - the part that attaches the cob to the plant), were collected from the same plants. The peduncles were swabbed with $100 \%$ ethanol and a similar segment to the above was removed from a peduncle cross-section and plated onto PPA. All cobs collected showed minimal cob rot but kernels (10) were removed from each cob randomly for isolation of Fusarium from each farm except those at Dubbo where cobs were not collected. Kernels were surface sterilised in $1 \%$ sodium hypochlorite with $10 \%$ ethanol for three min, rinsed in sterile distilled water, dried with sterile tissue and plated on PPA. Cultivars varied from region to region due to the requirements of the processor.

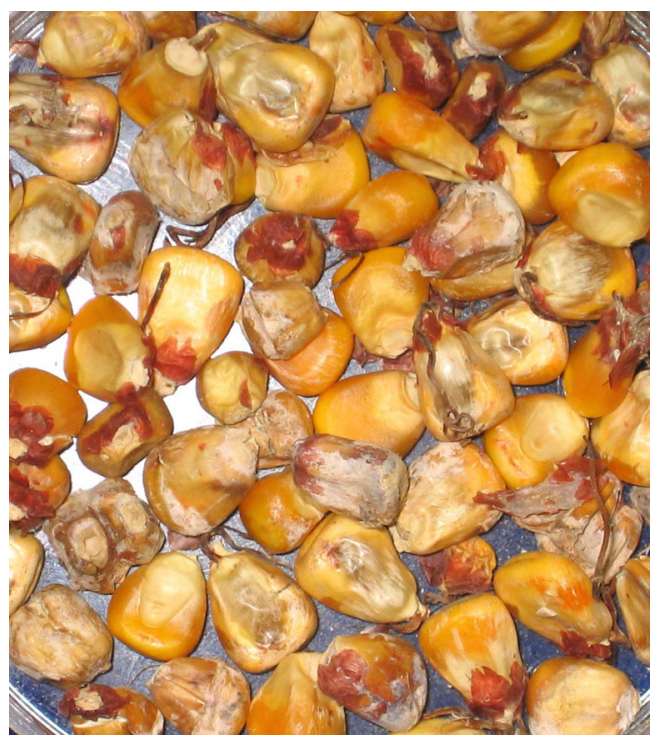

Fig. 1 Brown maize kernels infected with Fusarium verticillioides amongst yellow healthy kernels

For the maize cob rot outbreak a preliminary isolation from infected cobs (20) confirmed the cob infection was caused by F. verticillioides. An ad hoc survey of crops that were severely affected by cob rot in the Griffith area of the MIA was subsequently undertaken. Fifty stalks were collected from each of four affected crops in Griffith, and from a symptomless crop in the Dubbo area for comparison. Fifty cobs, including peduncles, were collected from six crops in Griffith. Fusarium species were isolated from all samples using the methods described above for the sweet corn survey.

Eighteen harvested grain (maize) samples that were submitted for fumonisin testing by growers from the MIA were examined to identify the dominant species of Fusarium associated with the infected grain. Five diseased grains from each sample were surface sterilised in $1 \%$ sodium hypochlorite with $10 \%$ ethanol for three min, rinsed in sterile distilled water, dried with sterile tissue and plated on PPA.

Table 1 The mean frequency of isolation of Fusarium species from each location for the sweet corn survey

\begin{tabular}{|c|c|c|c|c|c|c|c|c|c|c|c|c|}
\hline \multirow[t]{2}{*}{ Location } & \multicolumn{5}{|c|}{ F. verticillioides } & \multicolumn{4}{|c|}{ F. subglutinans } & \multicolumn{3}{|c|}{ F. proliferatum } \\
\hline & $\mathrm{S}^{1}$ & & $\mathrm{P}$ & & $\mathrm{K}$ & $\mathrm{S}$ & $\mathrm{P}$ & & $\mathrm{K}$ & $\mathrm{S}$ & $\mathrm{P}$ & $\mathrm{K}$ \\
\hline Bathurst & 1.3 & $\mathrm{a}$ & 1.3 & $\mathrm{a}$ & 6.7 & 42.7 & 39.3 & $\mathrm{a}$ & 46.7 & 0.7 & 0 & 3.3 \\
\hline Cowra & 26 & $\mathrm{~b}$ & 11 & $a b$ & 0 & 1 & 0 & $\mathrm{~b}$ & 0 & 3 & 6 & 20 \\
\hline Dubbo & 16.7 & $\mathrm{ab}$ & 12 & $a b$ & & 12 & 8 & $\mathrm{~b}$ & & 6 & 8 & \\
\hline Griffith & 32.7 & $\mathrm{~b}$ & 44.7 & $\mathrm{~b}$ & 20 & 6 & 4 & $\mathrm{~b}$ & 0 & 10.7 & 8.7 & 20 \\
\hline $\mathrm{P}$ & 0.028 & & 0.006 & & 0.296 & 0.137 & 0.085 & & 0.241 & 0.18 & 0.129 & 0.244 \\
\hline LSD $5 \%$ & 20.03 & & 21.07 & & ns & $\mathrm{ns}$ & 33.7 & & ns & ns & ns & $\mathrm{ns}$ \\
\hline
\end{tabular}

\footnotetext{
${ }^{1}$ Stalks $(S)$, Peduncles $(P)$, and Kernels $(K)$. Values expressed as a percentage of the total number of pieces of sweet corn sampled with each Fusarium spp. Values within a column with the same letter are not significantly different
} 
Table 2 The frequency of isolation of Fusarium species from maize at each location

\begin{tabular}{|c|c|c|c|c|c|c|c|c|}
\hline \multirow[t]{2}{*}{ Farm } & \multirow[t]{2}{*}{ Location } & \multirow[t]{2}{*}{ Cultivar } & \multicolumn{2}{|c|}{ F. verticillioides } & \multicolumn{2}{|c|}{ F. subglutinans } & \multicolumn{2}{|c|}{ F. proliferatum } \\
\hline & & & $\mathrm{S}^{1}$ & $\mathrm{P}^{1}$ & $\mathrm{~S}$ & $\mathrm{P}$ & $\mathrm{S}$ & $\mathrm{P}$ \\
\hline 1 & Griffith & $36 \mathrm{R} 10$ & 72 & 86 & 2 & 0 & 20 & 6 \\
\hline 2 & Griffith & 3,335 & 68 & 72 & 0 & 0 & 24 & 4 \\
\hline 3 & Griffith & $37 \mathrm{H} 24$ & 60 & 78 & 2 & 0 & 20 & 2 \\
\hline 4 & Griffith & $37 \mathrm{H} 24$ & 70 & 72 & 8 & 0 & 16 & 6 \\
\hline 5 & Griffith & $36 \mathrm{R} 10$ & & 60 & & 2 & & 8 \\
\hline 6 & Griffith & DL744 & & 50 & & 0 & & 10 \\
\hline 7 & Dubbo & Unknown & 40 & & 30 & & 5 & \\
\hline
\end{tabular}

${ }^{1}$ Stalks $(S)$ and Peduncles $(P)$, values are a percentage of the total number of pieces of maize sampled with each Fusarium spp

Fusarium colonies developing from the segments and kernels were subcultured onto Carnation Leaf Agar (CLA) (Fisher et al. 1982). These cultures were purified by transferring single germinated spores to CLA and Potato Dextrose Agar and grown for $7-10$ day with a $12 \mathrm{~h}$ photoperiod at room temperature.

All isolates were sorted morphologically using the characters outlined in Burgess et al. (1994) and Leslie and Summerell (2006), and identity was confirmed by determining the mating population and by sequencing the translation elongation factor (TEF) $1-\alpha$ gene according to the protocols of Summerell et al. (2003) and Leslie and Summerell (2006). At the time the isolates were identified there was not an extensive database of TEF sequences available to confirm the sequence identity.

Several Fusarium species were isolated from stalks, peduncles and kernels of sweet corn from all regions, with the most frequently isolated species being $F$. verticillioides, F. proliferatum, and F. subglutinans. Fusarium nygamai and $F$. graminearum were isolated infrequently. There were a small number of other species that were isolated at a very low frequency that were not identified and are not reported here. Frequency data was analysed for Fusarium species by plant part and location using Genstat ANOVA analysis of variance (11th Edition) (Table 1).

In the maize survey $F$. verticillioides was the dominant Fusarium species isolated from maize stalks (Table 2)

The dominant species from the maize grain samples was F. verticillioides, isolated from $82 \%$ of the grain and $F$. proliferatum isolated from $21 \%$ of grain. The findings of the surveys indicate that sweet corn and maize do not differ in respect of the Fusarium species associated endophytically with the plants, as assessed by the frequency of isolation.

Regional differences in climatic factors are likely to have influenced the relative frequency of isolation of the different Fusarium species. Fusarium subglutinans has been reported to occur more frequently in regions where climatic conditions are milder, where mean summer temperatures are cooler in contrast to $F$. verticillioides which appears to be better adapted to warmer regions where summer temperature means are higher (Edwards 1935, 1936; Marasas et al. 1979; Burgess et al. 1981; Bottalico 1998). Griffith and Dubbo are much hotter than Bathurst and it is presumed that these environmental variations have influenced the relative distribution of the dominant Fusarium species in NSW.

The cob rot in both sweet corn (that occurred in 2001/2002) and maize (that occurred in 2002/2003) appeared to be related to a combination of factors including susceptible cultivars and stress, including low irrigation water availability for the maize epidemic and for both sweet corn and maize heavy rainfall close to harvest. Two fumonisin-producing Fusarium species, F. verticillioides and F. proliferatum, were common in maize and sweet corn in this study.

This work coincided with the assessment of fumonisin levels in grain from many crops that were harvested so that some indication could be given to potential end users of the level of grain contamination (O'Keeffe 2003). The levels of fumonisin in 60 maize grain samples ranged from 0 to $10 \mathrm{ppm}$, with 17 crops higher than $5 \mathrm{ppm}$. Growers were able to grade the harvested grain to remove the lighter weight material, the Fusarium infected grain.

Low levels of $F$. graminearum were isolated in these surveys in contrast to its more frequent isolation from maize in the more temperate and wetter coastal regions of eastern Australia (Francis and Burgess 1975). Wakelin et al. (2008) examined Fusarium populations in soil used for maize production in Whitton (near Griffith and close to sites in this study) and reported low isolation rates of $F$. graminearum.

Both industries are aware of potential contamination issues in some seasons through extension and other education activities. Maize cultivar trials in growing regions provide ongoing information on new cultivars and tolerances to the local conditions in relation to stalk and cob rot frequency. Fumonisin and other mycotoxin contamination levels in maize continue to be monitored by stock feed companies and those companies involved in the manufacture of products for human consumption. 
Regular surveys of Fusarium species over successive growing seasons are warranted together with parallel studies of fumonisin contamination in order to better understand the relationship between seasonal conditions, stress and disease severity.

Acknowledgments This work has been partly funded by HAL using the vegetable levy and matched funds from the Australian Government. The technical assistance of Julie Bates, Meryl Snudden and Lee Browne is acknowledged gratefully.

\section{References}

Bacon CW, Porter JK, Norred WP, Leslie JF (1996) Production of fusaric acid by Fusarium species. Appl Environ Microbiol 62:4039-4043

Bottalico A (1998) Fusarium diseases of cereals: species complex and related mycotoxin profiles. Eur J Plant Pathol 80:85-103

Burgess LW, Dodman RL, Pont W, Mayers P (1981) Fusarium diseases of wheat, maize and grain sorghum in eastern Australia. In: Nelson PE Toussoun TA, Cook RJ (ed) Fusarium: diseases, biology and taxonomy. Pennsylvania State University Press

Burgess LW, Summerell BA, Bullock S, Gott KP, Backhouse D (1994) Laboratory manual for Fusarium research. The University of Sydney/The Royal Botanic Gardens, Australia

Desjardins AE (2006) Fusarium mycotoxins chemistry genetics and biology. The American Phytopathological Society, St Paul
Edwards ET (1935) Studies on Gibberella fujikuroi var. Subglutinans and its pathogenicity on maize in New south wales. Sci Bull NSW Dept Agric 49:1-68

Edwards ET (1936) Root and basal stalk Rot of maize. Agric Gazette 259-61

Fisher NL, Burgess LW, Toussoun TA, Nelson PE (1982) Carnation leaves as a substrate and for preserving cultures of Fusarium species. Phytopathology 72:151-153

Francis RG, Burgess LW (1975) Surveys of fusaria and other fungi associated with stalk rot of maize in eastern Australia. Aust J Agric Res 29:801-807

Leslie JF, Summerell BA (2006) The Fusarium Laboratory Manual. Blackwell Publishing

Marasas WFO, Kriek NPJ, Wiggins VM, Steyn PS, Towers DK, Hastie TJ (1979) Incidence, geographic distribution, and toxigenicity of Fusarium species in South African corn. Phytopathology 69:11811185

Nguyen TH (2005) Fusarium species associated with maize (Zea mays) in Northern Viet Nam, North Sulawesi, Indonesia and New South Wales, Australia, PhD Thesis, The University of Sydney

O'Keeffe K (2011) Maize the current situation and potential in Australia http://www.grdc.com.au/

O'Keeffe K (2003) Fusarium in the Riverina. Cob Mag 3:11

Shanks G, Tabak P, Begg AP, Bryden WL (1995) An outbreak of acute leukoencephalomalacia associated with fumonisin intoxication in three horses. Aust Equine Vet 13:17-18

Summerell BA, Salleh B, Leslie JF (2003) A utilitarian approach to Fusarium identification. Plant Dis 87:117-127

Wakelin SA, Warren RA, Kong L, Harvey PR (2008) Management factors affecting size and structure of soil Fusarium communities under irrigated maize in Australia. Appl Soil Ecol 39:201-209

White DG (1999) Compendium of corn diseases. The American Phytopathological Society, Minnesota 